\title{
Ceremonialismo y congregación durante la transición arcaico tardío y formativo temprano en la circumpuna de Atacama (norte de Chile) ${ }^{1}$
}

\author{
Lautaro Núñez² y Catherine Perlès ${ }^{3}$
}

\begin{abstract}
RESUMEN
En el borde occidental de la circumpuna del desierto de Atacama, a través de ecorefugios en áreas circunscritas, cazadores-recolectores del Arcaico Tardío de la fase Puripica-Tulán (ca. 2600 a 1900 AC), iniciaron un proceso de cambios "neolíticos" que incluyeron la domesticación y crianza de camélidos que culminó en la fase Tilocalar (ca. 1200 a 550/430 AC). Entre los sitios arcaicos tardíos Tulán-52 se destaca por la agregación de estructuras complejas que pueden considerarse como un prototipo de centro ceremonial. Su carácter innovativo continuó en el arquetipo del centro ceremonial del Formativo Temprano Tulán-54, en un tiempo cuando la subsistencia incluía caza, pastoralismo y horticultura. Dentro de un contexto de incremento de complejidad social ocurrieron diversos rituales asociados con festines en ambos centros ceremoniales. El tardío conduce a la acumulación de restos de alimentos, instrumentos y desechos de la producción de ornamentos, fogones y sedimentos, creando un montículo que deliberadamente cubrió las estructuras ceremonialistas bajo la conducción de liderazgos emergentes.
\end{abstract}

Palabras clave: Caza-pastoralismo, centro arcaico ceremonial, emergencia de complejidad, Tulán-52, circumpuna del desierto de Atacama.

\begin{abstract}
On the western side of the circumpuna in the Atacama Desert, along ecorefuges with favorable resources in the surrounding areas, the Late Archaic hunter-gatherers of the Puripica-Tulán phase (ca. 2600 to 1900 BC) initiated a process of "Neolithic" changes that included the domestication and breeding of camelids and that culminated in the Tilocalar phase (ca. 1200 a 550/430 BC). Among Late Archaic sites, Tulán-52 stands out by its aggregated and complex stone structures and can be considered as a prototype of ceremonial centres. Its innovative features continued in the archetypal Early Formative centre of Tulán-54, at a time when subsistence then included hunting, pastoralism and horticulture. Within a context of increasing social complexity, diverse rituals associated with feasting took place in both ceremonial centres. The latter led to the accumulation of food remains, tools and ornaments production remains, hearths and sediment, creating mounds that deliberately covered the ceremonial structures, under the guidance of emerging leadership.
\end{abstract}

Keywords: Hunting-pastoralism, archaic ceremonial centre, emergence of complexity, Tulán-52, circumpuna of the Atacama Desert.

El trabajo en el área de Tulán fue posible gracias a la colaboración de la comunidad atacameña de Peine y los colegas de varias universidades que constituyen el equipo Tulán (Fondecyt (1930022, 1020316, 1070040, 1130917). Especial mención al aporte del colega Patricio López M. por el perfeccionamiento de las figuras. Se destaca la colaboración entre el laboratorio UMR 7055 en Francia y el Instituto de Arqueología, Antropología y Museo de la Universidad Católica del Norte en San Pedro de Atacama, apoyado por los proyectos PICS y LIA-Mines de Francia. Artículo recibido el 30 de septiembre de 2017, aceptado el 23 de abril de 2018 y corregido el 27 de junio de 2018. Instituto de Arqueología, Antropología y Museo, Universidad Católica del Norte (Chile). E-mail: lautaro.nunez@hotmail.com Université Paris Nanterre, CNRS, UMR 7055, Préhistoire et Technologie (Francia).E-mail: catherine.perles@mae.u-paris10.fr 
Es propio de las comunidades humanas prehistóricas la aplicación de prácticas sociales que han involucrado eventos dinámicos de ritualización, correlacionados con los contextos de las actividades cotidianas almacenadas en las memorias sociales (Connerton, 1989; Ingold, 1990; Bradley, 2005; Brück, 1999). Esto significa que los componentes simbólicos y utilitarios o mundanos se integran a la data arqueológica por la propia naturaleza humana al percibir su relación con el entorno a través de gestos, acciones y materialidad ritualizada (Gosden \& Lock, 1998). En cuanto las acciones rituales responden a tradiciones y hábitos consuetudinarios, éstas se reiteran en el tiempo, de modo que es posible detectarlas a través de sus formatos estereotipados formalmente convencionales (Bradley, 2004, 2005; Bell, 1992). En esta dirección, desde una perspectiva teórica: “Tal efecto se consigue mediante la recurrente participación en vivencias, donde los conceptos culturales inmanentes se infiltran por todas las instancias sociales a través de preceptos rituales y simbólicos" [..] (Bell, 1992:118-142; Blanco, 2011:127). De manera que el proceso de ritualización se consolida por la repetición, perdurando y promoviéndose las actividades prototípicas (Connerton, 1989).

Desde esta percepción los eventos cíclicos de ritualización integran al cuerpo social con el ambiente geográfico asociado, acogiendo las demandas que responden a aspiraciones comunes para sustentar con fuerzas extra humanas las actividades domésticas, en cuanto los participantes lo han aceptado en el marco de sus propias pautas culturales. En este sentido los idearios ritualísticos formales no se separan entre el colectivo y los diversos grados de liderazgos bajo un orden regular al interior de una esfera de interacción que integra la vida doméstica con las prácticas rituales (Bell, 1992; Bradley, 2004, 2005; Brück, 1999).

Al interior de estas consideraciones generales el registro arqueológico arcaico y formativo en los Andes es diverso en evidencias ritualísticas con diferentes grados de complejidad, modalidades y materialidad, donde la arquitectura y la peregrinación adquiere un rol relevante que separa el tiempo real del ritual. Con particular énfasis en el culto hacia los ancestros humanos y telúricos, mediatizados con festines, en donde el rol de la alimentación fue determinante en diversas ceremonias que repercutían en la vida cotidiana. De modo que los rituales se sustentaron entre la vida y la muerte, basados en creencias que sacralizaban el poder de la tierra (Descola, 1996; Hastorf, 2007). Los tiempos de tensiones y de estrés estimulaban la concentración de fuerzas en la medida en que desde las memorias surgían las visiones del poder de los ancestros y del panteón andino, dando lugar a rituales que se nutren de la inclusión de las comunidades. Se trata de eventos comunales hacia donde convergen y se congregan agrupaciones que responden a las performances preestablecidas: "Thus, even foods consumed during ritual time are different from the same dish consumed in daily life" (Hastorf, 2007: 99). Actos considerados como banquetes no domésticos con relaciones de comensalismo en un marco de abundancia, hospitalidad y, en ciertos casos, de aplicación de fuerzas de trabajo (Dietler \& Herbich, 2001; Dietler \& Hayden, 2001; Hayden, 2001; Kaulicke, 2005).

Con este marco de referencias teóricas y conceptuales es posible introducir un cuerpo de datos e interpretaciones de un asentamiento arcaico tardío, ubicado en la circumpuna de Atacama (Norte de Chile), en donde se ha identificado un patrón arquitectónico que responde a prácticas rituales inmediatamente anteriores a la emergencia de sociedades complejas formativas. Al respecto, la identificación de ocupaciones humanas arcaicas de naturaleza cazadora-recolectora con componentes que representen indicios de emergencia de complejidad es uno de los objetivos latentes en la problemática arqueológica andina. En este estudio se acoge esta orientación, 
valorando el sitio Tulán-52, ubicado al sureste de San Pedro de Atacama, sometido a un metódico decapado de sus estructuras y depósitos estratificados con el fin de evaluar sus contextos culturales y subsistenciales debidamente cronologizados. Se comparan sus atributos y aportes a través de otros asentamientos contemporáneos y posteriores en el área con aquellos sitios sincrónicos extra andinos con afinidades en términos de cambios "neolíticos" iniciales. Al enfatizar las evidencias arquitectónicas y contextuales, incluyendo el proceso de formación de sitio, se concluye que el sitio arcaico tardío Tulán-52 reúne los requisitos para considerarlo como un proto centro ceremonial complejo. Aquí se habrían congregado temporalmente inter bandas en torno a comidas colectivas y ritos asociados que se trasfirieron en la próxima fase formativa Tilocalar, representada en el más sofisticado centro ceremonial del sitio Tulán-54.

\section{Reconstitución del escenario geográfico}

Las relaciones entre cambios climáticos y paleoambientes han impactado en los asentamientos humanos durante la secuencia prehistórica de las Américas y en este sentido el paisaje andino no ha sido una excepción, particularmente en los ecosistemas áridos más sensibles a las variaciones de humedad, generando diversos ajustes adaptativos (Bonnichsen et al., 1987; Bindford \& Kolata, 2001; Grosjean \& Núñez, 1994; Grosjean et al., 1995; Moseley, 1997; Sandweiss et al., 1998; Seltzer y Hastorf, 1991). Durante la transición Pleistoceno-Holoceno Temprano las condiciones de humedad fueron óptimas en el centro sur andino con recursos extensivos que favorecieron el mayor poblamiento arcaico en el espacio circumpuneño y las quebradas que drenan a la cuenca del salar de Atacama por los 11000 - 8000 años AP (Sylvestre et al., 1999; Grosjean et al., 2001b, 2005a, 2005b; Núñez et al., 2005-a). Sin embargo, posteriormente durante el Holoceno Medio las lluvias fueron menores, generando un hiato seco hasta los 3600 a 3000 años AP, cuando se recuperó el régimen pluvial y los lagos retornaron a sus niveles altos, tanto en el altiplano como en la circumpuna (Abbott et al., 2003; Valero Garcés et al., 1996; Núñez et al., 1999).

Durante este intervalo seco desde las tierras altas altiplánicas a la circumpuna occidental y oriental transandina prevalecieron condiciones críticas de habitabilidad (Aschero et al., 1991; Messerli et al., 1993). No obstante, existieron locis aislados con recursos estables que estimularon la concentración discreta de agrupaciones de cazadores y recolectores en ecorefugios donde pervivieron y se especializaron en la explotación de nichos favorables con menos movilidad e intensificación del manejo oportunístico de espacios restringidos (Benedict, 1978; Grosjean \& Núñez, 1994; Núñez et al., 1999).

Los análisis interdisciplinarios limnológicos y sedimentológicos logrados en las perforaciones realizadas en la laguna Miscanti, en la cabecera de la quebrada Tulán, permitieron reconocer un rápido proceso de regresión del nivel lacustre, hasta la exposición del fondo a erosión subaérea (Grosjean et al., 2001a; Valero Garcés et al., 1996). Este intervalo seco fue tan drástico que en esta laguna la regresión de su espejo provocó que ciertas agrupaciones de cazadores recolectores hayan consumido preferentemente los camélidos cazados en los humedales expuestos, dada la sincronía datada entre un campamento situado en una paleo playa con el clímax del intervalo árido (Grosjean et al., 1997; Núñez et al., 2018; Sylvestre et al., 1999).

Estas evidencias de un cambio climático regional tan drástico, cercano a Tulán, no lograron alterar los recursos locales de la quebrada, por cuanto se mantuvo el arroyo generado en vertien- 
tes que no fueron afectadas por el déficit pluvial y con ello los humedales situados bajo los 3000 $\mathrm{m}$, una altura óptima para ocupaciones humanas más estables, localizadas bajo el rigor de la alta puna. Se habrían creado condiciones favorables que estimularon respuestas complejas, provocando cierta restricción de la movilidad arcaica con más dependencia de este "oasis" rodeado de extensas planicies y piemontes estériles. En consecuencia, se generó un efecto de convergencia en torno a prácticas de caza, recolección y domesticación de camélidos, toda vez que también la fauna optó por ocupar estos recursos aislados, cuando los lagos estaban secos y disminuyó en general el potencial forrajero (Grosjean et al., 2003; Núñez et al., 1999).

Ciertamente, el intervalo árido generó sequías dramáticas con desajustes en términos de flora, fauna y potencial hídrico, creándose un escenario de estrés paleoambiental durante el Holoceno Medio, dando lugar en la circumpuna de Atacama a una crisis demográfica reflejada en la sensible disminución de campamentos arcaicos entre los 8000/7000 a 5000 años AP, caracterizada como un tiempo de déficit de recursos (Núñez et al., 1999; Núñez et al., 2005a). De modo que el ecorefugio de Tulán, aunque coincide con el intervalo árido regional, identificado en Miscanti, se distingue por presentar ocupaciones humanas reconocidas en varios sitios representados en Tulán-52, asociado a importantes paleohumedales (Rech et al., 2002) esenciales para el acercamiento de camélidos, lo que explica que las agrupaciones congregadas en este sitio se hayan especializado en su captura y aun iniciaron el proceso de domesticación (Cartajena et al., 2007). En este caso, los atributos favorables del ecorefugio se ciñen a agua potable del arroyo, recolección de vegetales silvestres alimenticios como las raíces de Scirpus, frutos, posiblemente de chañar (Geoffrea decorticans), tratados sobre morteros, canteras líticas de óptima calidad para el utillaje, extensos humedales (paleovegas) y combustible arbóreo, entre otros. En este marco de referencia es posible que la propia fecundidad excepcional de la quebrada Tulán haya estimulado congregaciones temporales inter bandas en torno a comidas y ritos ceremonialistas colectivos, tal como se ha observado en Tulán-52. Estas acciones de cierta estabilidad inicial, al optimizar los recursos in situ, crearon un tránsito innovador hacia la emergencia de comunidades formativas complejas, integradas con mayor permanencia agropastoralista, asociadas esta vez a arquitectura residencial, áreas de inhumaciones, incluyendo un centro ceremonial identificado en el sitio Tulán-54 (Núñez et al., 2017).

\section{Antecedentes generales}

Durante la transición arcaico-formativa se han valorado diversos centros ceremoniales complejos en los Andes centrales y meridionales, con una particular orientación agropastoralista en las tierras altas asociadas a congregaciones y festines rituales (Hastorf, 2008). A pesar de su aparente aislamiento actual en el extremo sur del salar de Atacama, a los $2700 \mathrm{msnm}$, el pequeño valle de Tulán no es una excepción a su debida escala y proceso representativo de la circumpuna de Atacama. Prospecciones y excavaciones intensivas revelaron un proceso local de domesticación y crianza de camélidos, asociado a la identificación de un importante centro ceremonial formativo: Tulán-54 (Cartajena, 2013; Cartajena et al., 2007; Núñez y Santoro, 2011; Núñez et al., 2005b, 2006a, 2017). En este sentido, el proceso de "neolitización" es aquí equivalente al tránsito de formaciones arcaicas cazadoras-recolectoras hacia comunidades formativas tempranas, sustentadas en caza y crianza de camélidos, con labores hortícolas durante la fase Tilocalar. Precisamente, se considera que el sitio Tulán-54 (ca. 1250 - 650 AC) marca la culminación de un proceso 
de crecimiento progresivo de complejidad socio-económica, derivado de trasformaciones locales de naturaleza cazadora-recolectora, identificadas en el sitio Tulán-52 (De Souza et al., 2010; Núñez et al., 2006a).

Estos cambios ocurrieron a través de encuentros para-sedentarios durante eventos intermitentes con intercambios sociales, experiencias religiosas, festines colectivos y productividad de bienes comunes. En efecto, el sitio parcialmente excavado Tulán-52 (ca. 3450 - 2250 AC) ha sido considerado como un caso representativo de la fase arcaica tardía, asociado a las primeras evidencias de un proceso de complejidad creciente. Presenta estructuras circulares aglomeradas, pertenecientes a cazadores complejos que acceden temporalmente a un espacio construido que, desde nuestras expectativas, amerita ser interpretado como un posible prototipo de centro ceremonial. Sus fuentes de subsistencia se sustentaron en la caza e inicio de domesticación de camélidos, colecta de calabazas (Lagenaria sp.), tunas (Opuntia sp.), frutos de chañar (Geoffrea decorticans) y cola de zorro (Cortaderia atacamensis) (Cartajena et al., 2007; Núñez et al., 2006a).

Sin embargo, es sabido que no existen criterios universales que permitan distinguir entre sitios habitacionales y ceremoniales, incluso cuando esa distinción es aplicable no siempre se han dado los indicadores suficientes. En el caso de Tulán-52 se reconocen contextos arcaicos con descartes de comidas colectivas, derivados de festines incipientes y labores cotidianas, ocurridos durante eventos sociales intermitentes junto a estructuras de uso no residencial. La congregación en recintos de uso ritualístico durante la fase arcaica Puripica-Tulán (ca. 2600 - 1900 AC) persistió en una escala de mayor complejidad en la fase posterior Tilocalar (ca. 1200 - 550/430 AC), donde se destaca el sitio Tulán-54, un centro ceremonial caracterizado por la locación nuclear de un templete, limitado por un muro perimetral con estructuras interiores. Presenta componentes ceremonialistas explícitos: rasgos arquitectónicos monumentales, lajas grabadas, entierros de infantes y ofrendas jerárquicas (Núñez et al., 2006a, 2017).

En cambio, a pesar de poseer una arquitectura comparativamente más discreta, su antecesor Tulán-52 se caracteriza también por el empotrado de bloques verticales en el piso estéril, socavados circulares en los pisos de las estructuras, prácticas de molienda, un par de nichos o portales compuestos por dinteles, dispuestos sobre dos pilares, además de bloques muebles con grabados lineales, tecnologías líticas, grabación sobre huesos, perforadores y escasas cuentas líticas, óseas y de minerales de cobre de color. Estas evidencias continuarán registrándose en el templete del sitio Tulán-54, incluyendo las congregaciones grupales cíclicas o intermitentes en torno a comidas ritualizadas con abundantes restos de camélidos, cuyos descartes in situ, o como residuos secundarios movilizados, también cubrieron gradualmente las estructuras fundacionales, conformando un túmulo, tal como sucedió antes en Tulán-52. La ausencia aquí de entierros humanos en su interior, de manufacturas complejas: cerámica, metales, cestería, incluyendo objetos de prestigio y muro periférico, entre otros rasgos, se atribuye a su datación anterior y su carácter arcaico.

\section{La ocupación prehistórica temprana del salar de Atacama}

El transecto Tulán a lo largo de la quebrada del mismo nombre, se ubica al sureste del salar de Atacama $\left(22^{\circ} \mathrm{S}-24^{\circ} \mathrm{S}\right)$, a más de $2500 \mathrm{msnm}$, en la ladera oeste de la alta Puna de Atacama situada 
en los Andes meridionales (Figura $\mathrm{N}^{\circ} 1$ ). El desierto de Atacama es una de las regiones más secas del mundo, con precipitaciones anuales actuales menores a $20 \mathrm{~mm}$, precisamente en el salar de Atacama, pero alcanza los $2000 \mathrm{~mm}$ en las tierras altas sobre los 5000 msnm (Núñez et al., 2002, 2013). Las primeras ocupaciones humanas datan de la fase Tuina, del Arcaico Temprano (ca. 10150 - 7150 años AC), bajo un clima mucho más húmedo que el de hoy, con precipitaciones estimadas en ca. 200 mm anuales en la cuenca de Atacama (Geyh et al., 1999; Grosjean et al., 2005a, 2005b, 2007; Núñez et al., 2002, 2005a). Las agrupaciones de cazadores-recolectores móviles ocuparon cuevas y refugios rocosos, incluyendo las quebradas intermedias (3600 - $3000 \mathrm{msnm}$ ) y los oasis más bajos, aunque también ascendieron estacionalmente a los paleolagos de la alta puna sobre 4000 m. Cazaban principalmente camélidos (Lama guanicoe y Vicugna vicugna), además de los últimos équidos de fines del Pleistoceno (Núñez et al., 2002).

Figura $\mathrm{N}^{\circ} 1$

Ubicación del sitio Arcaico Tardío Tulán-52 y del Formativo Temprano Tulán-54, asociado a otros sincrónicos en la fase Tilocalar, localizados en el transecto Quebrada Tulán - salar de Atacama

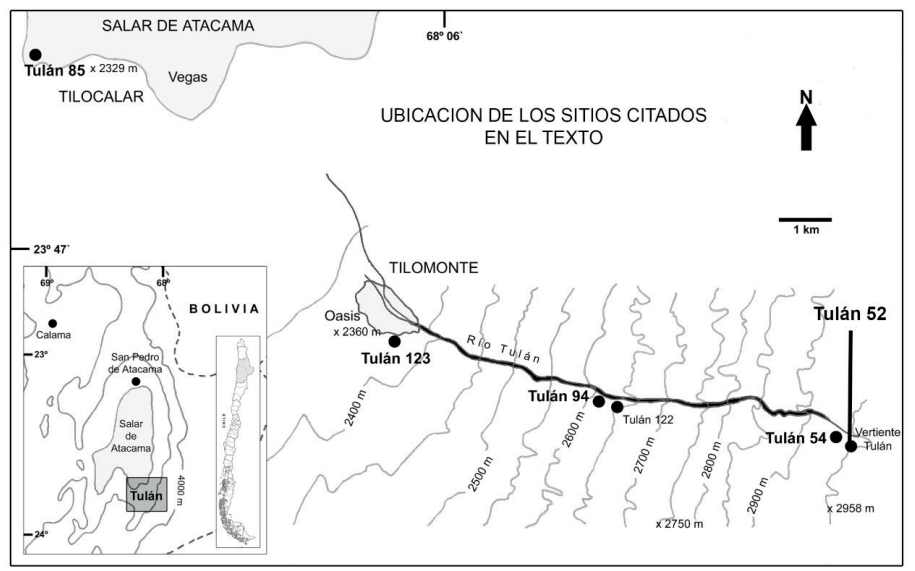

Fuente: Proyecto FONDECYT No 1130917.

Durante la siguiente fase Tambillo (ca. 7050 - 6050 AC) la explotación de la alta puna se incrementó, pero los asentamientos de larga duración se concentraron mayormente en los márgenes bajos del salar, donde había recursos disponibles todo el año. La caza se enfocaba en camélidos, mientras que grandes morteros con típicas depresiones cónicas indican la explotación intensiva de frutos silvestres de árboles nativos como el chañar (Goeffraea decorticans). El campamento Tambillo-1 se concentra en torno a los humedales y relictos lacustres en el borde oriental del actual salar de Atacama y está vinculado con un primer cementerio indicador de cierta estabilidad. Comprendía viviendas circulares con pisos levemente socavados, asociados a una industria típica de puntas de proyectiles triangulares aplicadas en propulsores. Se han observado contactos de larga distancia por la presencia de obsidiana proveniente de las tierras altas y conchas del Pacífico (Olivia peruviana) (Núñez y Santoro, 2011). 
La dinámica propia de estas ocupaciones semi-sedentarias y la explotación especializada de recolección de plantas y caza de animales, pre requisitos del proceso de "neolitización", habrían sido interrumpidas por la aridez e inestabilidad del patrón climático que se inició alrededor de 7000 AC. La severidad del intervalo árido, con escalas y temporalidad variables, contrasta con el régimen húmedo del Holoceno Temprano (Grosjean et al., 2007; Latorre et al., 2005; Núñez et al., 2013). La variabilidad climática del Holoceno Medio en el desierto de Atacama sería heterogénea, con una rápida alternancia entre cortos periodos húmedos/secos (Grosjean et al., 2003; Latorre et al., 2003; Rech et al., 2003). Sin embargo, el efecto dramático de aridez en la circumpuna de Atacama implicó un impacto en las poblaciones cazadoras-recolectoras. Los paleolagos de la alta puna se secaron, conformando humedales, mientras que la mayoría de los campamentos altos de los patrones Tuina, Tambillo y San Martin fueron abandonados, tal como se advierte en los depósitos de capas estériles que rellenaron las cuevas y los refugios rocosos sobre las ocupaciones tempranas, localizadas en los pisos más bajos. Es decir, durante el intervalo seco se observa un marcado descenso en la densidad de los asentamientos, lo que se ha denominado "silencio arqueológico" (Núñez et al., 2002, 2013). Por otro lado, estas condiciones ambientales adversas estimularon la ocupación de ecorefugios con recursos favorables circunscritos, dependientes de vertientes estables, tal como ocurrió en la quebrada de Tulán (Figura № 2).

Al norte del salar de Atacama, en el área de Puripica, el estancamiento de un arroyo lateral condujo a la creación de lagos poco profundos, mientras que hacia el sur la quebrada de Tulán se benefició de un flujo perenne, apto también para la concentración de camélidos, en el mismo tiempo en que el lago Miscanti, ubicado en la cota más alta del transecto, permanecía seco, afectado por erosión subaérea con restos de fecas de camélidos que usufructuaban del humedal donde había regido un ambiente lacustre (Grosjean et al., 2007; Núñez et al., 1999).

Los recursos en estos ecorefugios pueden haber sido limitados en variedad, pero eran lo suficientemente abundantes y estables como para permitir ocupaciones móviles de baja densidad, asociadas a transformaciones culturales progresivas, vinculadas a estrategias de movilidad e intensificación, documentadas en Puripica-1 (Grosjean et al., 1997, 2007). A comienzos del Arcaico Tardío (ca. 3650 - 2250 AC) se identificaron en este sitio de agregación (3550 AC) agrupaciones con recintos circulares y semicirculares asociados a bloques muebles con grabados de camélidos del estilo Kalina-Puripica, construidos con lajas verticales empotradas (Núñez et al., 1999, 2006a; Núñez y Santoro, 2011). En efecto, estos asentamientos de la fase Puripica-Tulán, en ambas quebradas, se sitúan en alturas medias sin límites estacionales entre 2000 y 3000 msnm, junto a recursos de agua potable, espacios fértiles acotados, forraje, humedales y canteras eficientes donde se concentraba un locus de recursos faunísticos y vegetales. Las herramientas líticas eran más diversificadas que en los períodos anteriores, aplicadas principalmente en labores de caza, faenamiento y molienda, entre otras, incluyendo perforadores para la producción de cuentas. El uso de materiales exóticos como obsidiana, indica movilidad hacia la alta puna, y la presencia de numerosas conchas del Pacífico demuestra contactos con la costa, particularmente con la desembocadura del río Loa. Se ha reconocido que fueron mayormente cazadores de camélidos grandes y pequeños, Lama guanicoe y Vicugna vicugna, pero un descenso en el tamaño medio y un incremento en la variabilidad entre los especímenes más grandes, que no se pueden relacionar a factores climáticos, sugieren que las prácticas de domesticación estaban vigentes y que ya se contaba con llamas (Lama glama) criadas en cautiverio (Cartajena, 2009, 2013; Hesse, 1982). Tanto los especímenes salvajes como los domésticos fueron los iconos más reiterados en los 
bloques grabados en Puripica-1, en respuesta a los idearios de caza y pastoralismo incipiente. Por otra parte, la abundancia de morteros cónicos en Puripica y Tulán, heredados de la fase Tambillo, atestigua el uso continuo de recursos vegetales, al igual que el procesamiento de pigmentos. Durante la fase Puripica-Tulán la presencia de restos de calabazas (Lagenaria sp.) en niveles altos muestra que, paralelo a la domesticación incipiente, habían comenzado ciertas prácticas hortícolas (Núñez y Santoro, 2011). Por otro lado, la escasa presencia de semillas de chañar y posiblemente de algarrobo en Tulán-52 sugiere que eran transportadas y transformadas en harina o bien consumidas aguas abajo (ca. $25 \mathrm{~km}$ ), directamente en el oasis forestado de Tilomonte.

Figura $\mathrm{N}^{\circ} 2$

Panorama desértico de las tierras altas de la Puna de Atacama y ubicación del ecorefugio fértil de la quebrada Tulán. La flecha indica el sitio arcaico tardío Tulán-52

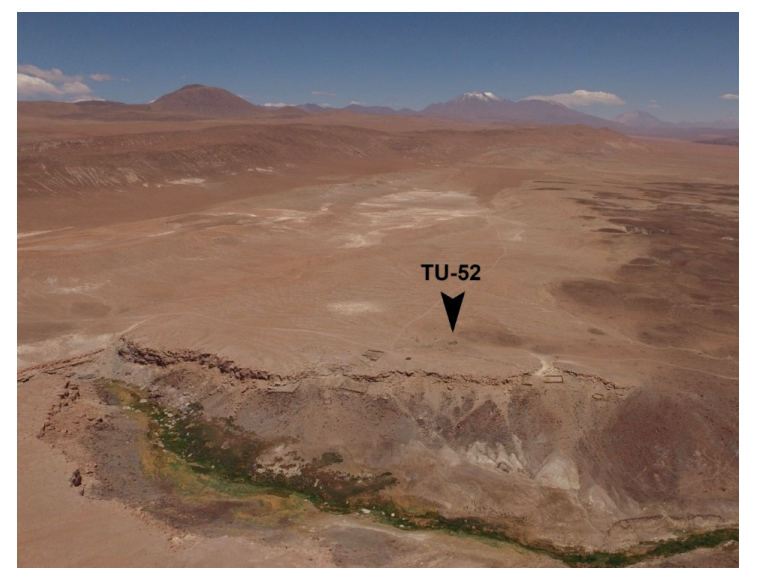

Fuente: Elaboración propia. Archivo fotográfico gentileza de Gonzalo Pimentel.

El pastoreo y la horticultura quedaron bien establecidos durante la próxima fase transicional Tarajne del Formativo Temprano (ca. 1850/1650 - 1160 AC), identificada en Tulán precisamente cuando se reestablecen las condiciones húmedas post Holoceno Medio, oportunidad en que se presentan componentes combinados con morteros cónicos del patrón Tulán-52 junto al temprano ingreso de cerámica, metates de molienda por fricción y el comienzo del laminado de oro, y otras tecnologías que se incrementarán en la próxima fase Tilocalar (ca. 1150 - 550/430 AC). Los camélidos salvajes (Vicugna vicugna) continuaron cazándose al mismo tiempo que se criaban las especies domésticas (Lama glama). Estos cambios se suceden estimulados, al parecer, por el término del intervalo árido y el advenimiento de condiciones más húmedas que condujeron al mejoramiento de los humedales piemontanos. Paralelamente, se expandieron los lagos de altura y el crecimiento forrajero de interfluvio, además del incremento de los caudales fluviales y, por cierto, se contaba con la experiencia acumulada por las ocupaciones humanas en los ecorefugios. De modo que el aumento de la disponibilidad de agua significó la recuperación generalizada de toda el área, más allá de los enclaves de Puripica y Tulán, con la explotación mutuamente complementaria de todos los recursos entre las tierras altas y bajas (Grosjean et al., 2007; Núñez et al., 1999; Núñez y Santoro, 2011; Núñez et al., 2006a). 
Junto a las prácticas dominantes pastoralistas y de caza se integraron, al final de la fase Tarajne y comienzo de la próxima Tilocalar, las prácticas hortícolas locales de escasa representatividad o recibidos, quizás por operaciones de intercambios, productos de uso muy selectivo aplicados en rituales como el maíz (Zea mays), otros más alimenticios, representados por quínoa (Chenopodium quinoa), oca (Oxalis tuberosum), ajíes (Capsicum sp.) y cucurbitas (Cucurbita sp.). La horticultura era practicada en el fondo de las quebradas, pero no reemplazó la explotación de plantas silvestres (Holden, 1991; Núñez et al., 2009).

Durante la fase formativa Tilocalar la extracción minera, metalurgia del cobre, oro y plomo, cerámica monocroma, arco y flechas, cestería (coiled), metates mayoritarios y altísima producción de cuentas constituyen, entre otros, innovaciones como la arquitectura ceremonial, y la consolidación de las primeras agrupaciones móviles pastoralistas formativas condujo a la producción de bienes de prestigio como un medio de interactuar en una escala espacial mayor (vide infra: Tulán-54). La ubicación de los asentamientos formativos y los conceptos arquitectónicos básicos son similares a la fase arcaica Puripica-Tulán, pero más densos y complejos, incluyendo estructuras ceremoniales y cementerios distintivos. Algunas de las lajas utilizadas en la construcción del centro ceremonial de Tulán-54 poseen petroglifos y pictografías que responden a la introducción intra templete del arte rupestre público a gran escala, identificado en ambas quebradas, representando principalmente diseños de camélidos naturalísticos. Efectivamente, los estilos Confluencia y Taira - Tulán muestran escenas de caza e íconos pastoralistas en la quebrada Tulán, como en el templete, que caracterizan a múltiples ocupaciones sincrónicas localizadas en un amplio espacio de la circumpuna occidental durante el Formativo Temprano. La concentración de estas manifestaciones rupestres en quebrada Tulán se vincularía con los recursos óptimos y estables de agua, concentración de camélidos, plantas y canteras útiles, a través de ritos públicos que se incorporan esta vez al templete. Hasta aquí convergen las agrupaciones dispersas de cazadores y pastores a los eventos ceremonialistas recurrentes, primero en el centro de Tulán-52 y posteriormente en el más complejo Tulán-54. Una vez consumadas las acciones colectivas, habrían retornado a sus prácticas móviles y dispersas a lo largo del transecto entre las tierras altas y el borde del salar (Capriles, 2014; López et al., 2013; Núñez et al., 2006b).

\section{Tulán-54: un centro ceremonial arquetípico}

La culminación del proceso de cambios, iniciado durante el período Arcaico Tardío (Tulán-52), radicó en las comunidades formativas tempranas, documentadas en el cercano centro ceremonial correspondiente al sitio Tulán-54. Su arquitectura específica, la escala y su organización interior requirió de considerable gasto energético, con cuantiosa aplicación de mano de obra y diversas acciones ceremonialistas. Estas incluyeron la preparación y consumo de comidas y bebidas in situ, además del traslado mezclado de descartes de festines exteriores y de desechos de labores. En este sentido, Tulán-54 es un centro ceremonial plenamente desarrollado que puede definir el carácter diagnóstico de la ritualidad del templete y de su entorno, hasta ahora extrañamente único en el espacio circumpuneño (Figura $N^{\circ} 3$ ).

El centro ceremonial se localiza en la cabecera del arroyo precordillerano Tulán, generado en vertientes a los 2969 msnm, y fue ocupado inicialmente alrededor de 1500 a 1130 AC antes de la construcción del templete. Este se sitúa rodeado de varias estructuras complementarias de uso 
Figura $\mathrm{N}^{\circ} 3$

El templete del Centro Ceremonial Tulán-54 del Formativo Temprano (1250-650 AC). La flecha indica el espacio de la inhumación de un infante asociado a la lámina de oro adjunta que representa un icono antropozoomorfo de cabeza radiada
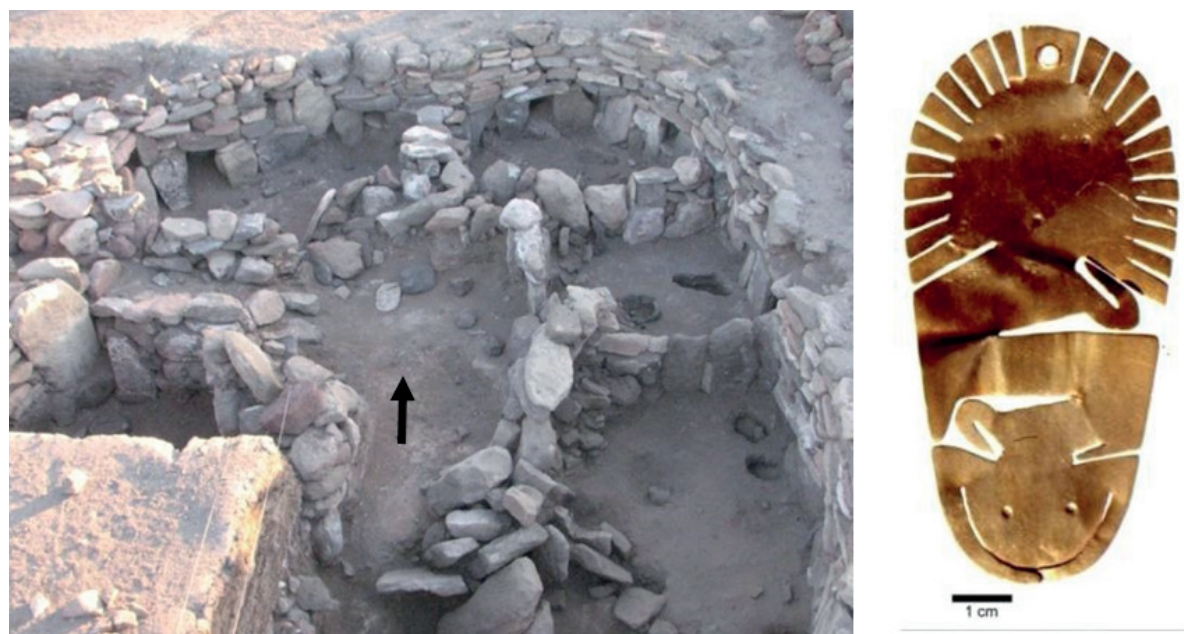

Fuente: Proyecto FONDECYT Nº 1130917.

ritual y fue construido alrededor de 1110 a 900 AC, permaneciendo en uso hasta ca. 770 a 360 AC (Núñez y Santoro, 2011; Núñez et al., 2005b, 2006a, 2017). Se trata de una estructura ovalada monumental, delimitada por una pared perimetral maciza con grandes lajas verticales cubiertas por una variedad de bloques horizontales. Incluye varios nichos construidos con grandes pilares verticales y dinteles, comunicados con cámaras extra muro perimetral. El área circunscrita presenta un piso excavado de aproximadamente 90 metros cuadrados, dividido en recintos más pequeños a través de paredes radiales que se unen a una estructura central subcircular donde se situaron inhumaciones de infantes con ofrendas sofisticadas.

En los pisos de los recintos interiores se documentaron 10 fogones delimitados por fragmentos de metates de molienda, asociados a fosos que contenían las inhumaciones de 28 infantes junto a la base de los nichos. Fueron acompañados por numerosas ofrendas mortuorias, como propulsores de hueso (lanza-dardos), láminas líticas talladas sin uso, contenedores de cestería (coiled), vasijas líticas grabadas con figuras de camélidos antropomorfizados, cuentas de crisocola, conchas del Pacífico (Oliva peruviana) y caracoles de tierra del trópico transandino (Strophocheilus oblongus). De un metate de molienda, ubicado en la inhumación de un infante (Núñez et al., 2009), fueron extraídas células de almidón de maíz intrusivo. En la estructura central, dos de los cuatro entierros contenían dos grandes colgantes antropomorfos de oro de manufactura laminar muy elaborada con el rostro radiado (ver Figura $N^{\circ} 3$ ). En otra inhumación, junto al muro periférico, se registró la ofrenda de un objeto como tapón elaborado en madera, cubierto con una lámina de oro repujado que representa a un cóndor con ojos y cresta de malaquita, asociado a una datación directa coherente de 690 a 540 AC (Richardin et al., 2017).

Sobre las ofrendas fundacionales ocurrieron reiteradamente actividades de combustión con restos de comidas y otros desechos, junto a descartes secundarios redepositados y mezclados 
entre ceniza, carbones, huesos de camélido, artefactos y desechos líticos, pigmento rojo, mineral de cobre, conchas y, principalmente, microperforadores asociados a la elaboración excedentaria de cuentas. Alrededor del templete se registran emplantillados y acumulamientos de rocas que corresponden a roles ceremoniales sobre inhumaciones de adultos. Estas poseen artefactos similares a aquellos encontrados en el relleno del templete, aunque por su ubicación y profundidad podrían ser posteriores al momento fundacional. No se descartan otras estructuras complejas en amplios espacios aún no excavados e insinuados por la aplicación de georadar (Núñez et al., 2016).

Aunque se ha dicho que resulta difícil diferenciar entre vestigios de actividades domésticas y las ritualísticas, los desechos de ciertas labores frecuentes como la preparación de comidas (residuos de camélidos y vasijas tiznadas) y bebidas (abundancia de contenedores de líquidos), y los componentes frecuentes del centro ceremonial, son suficientes para aceptar la congregación en este centro sacralizado. Se trataría de agrupaciones allegadas desde espacios relativamente aledaños, vinculadas con las prácticas de caza y pastoreo, que se incorporaban a rituales colectivos y festines de recurrencia temporal (Núñez et al., 2005b, 2017; Schmidt, 2005).

Precisamente, actividades aparentemente domésticas como la elaboración de cuentas en Tulán-54 adquieren una connotación ritual. Al respecto, unos 5000 perforadores líticos y abundantes fragmentos de óxido de cobre y conchas en el templete muestran que la producción excedentaria de adornos implicaba roles ideológicos, directamente relacionados con el centro ceremonial cuando las agrupaciones subalternas de permanencia temporal producen bienes cuantiosos de valor simbólico, organizadas por el liderazgo local.

Se entiende que los grupos movilizados hacia el centro ceremonial y sus aportes en términos de fuerzas de tareas, retribuidos con festines y performances ritualizadas, incrementaron las operaciones de intercambio internas y externas, en un escenario controlado por los líderes locales (Brown \& Kelly, 2015). En efecto, numerosos metates, manos y plataformas líticas planas evidencian la preparación recurrente de pigmentos, principalmente rojos, y los abundantes contenedores de comida y bebidas dan cuenta de acciones colectivas excepcionales. Mientras que los alucinógenos de semillas de cebil (Anadenanthera sp.), maíz (Zea mays) y almidón de maíz, también de uso ritual, ausentes en los depósitos estratificados, fueron identificados entre los infantes en el piso del templete, importados desde las tierras bajas del noreste argentino con fines probablemente chamanísticos (Núñez et al., 2009). Finalmente, en el último periodo de uso del templete fue establecido a unos 50 metros el cementerio Tulán-58, con inhumaciones de adultos e infantes, cuyas posiciones mostraban una mezcla de tradiciones arcaicas y formativas, posiblemente de agrupaciones procedentes de diversos espacios del transecto Tulán, enterradas en un espacio considerado sacralizado como un todo (Núñez et al., 2006a).

\section{Tulán-52: un prototipo de centro ceremonial circumpuneño}

El sitio temprano Tulán-52, ubicado a solo un km de Tulán-54 y a 2.969 m de altitud, en un contexto geomorfológico similar, con seis dataciones entre 3450 y 2250 AC, corresponde a instalaciones nucleadas en estructuras circulares aglomeradas que cubren una planta decapada del 
orden de los $64 \mathrm{~m}^{2}$, además de densas ocupaciones situadas en espacios abiertos de su entorno, vinculadas a actividades de consumo con fogones expuestos y restos de talla lítica, datados algo más temprano que el comienzo de ocupación del locus construido (Figura $\mathrm{N}^{\circ} 4$ ).

Figura $\mathrm{N}^{\circ} 4$

Las estructuras postdecapado del Centro ceremonial Arcaico Tardío Tulán-52

(3450-2250 AC)

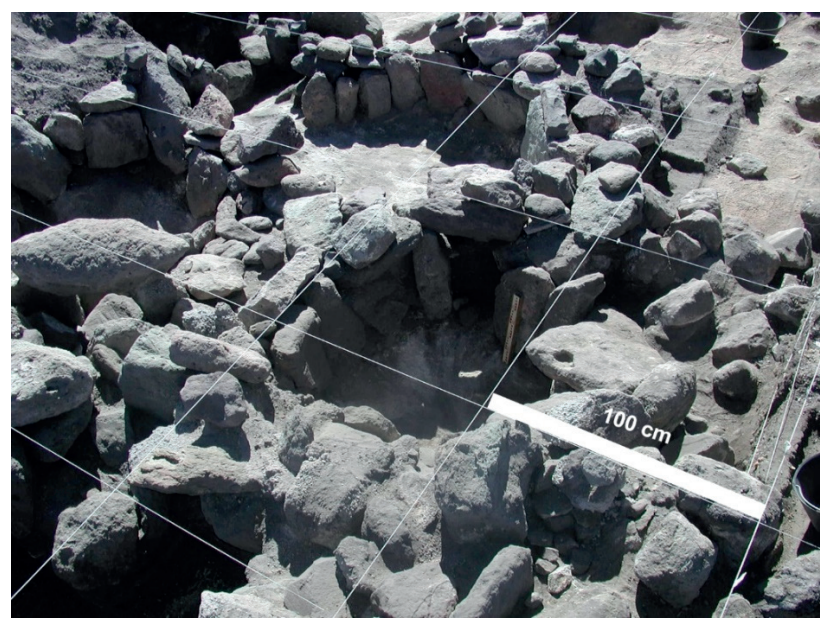

Fuente: Proyecto FONDECYT No 1130917.

Este sitio se ha interpretado como una ocupación aglomerada no permanente, con recintos semi-subterráneos y componentes rituales que continuaron en la próxima fase Tilocalar: tecnología lítica de láminas, proyectiles bifaciales foliáceos (Figura $N^{\circ} 5$ ), prácticas de molienda en morteros de hueco cónico (Figura $\mathrm{N}^{\circ} 6$ ), litos pulimentados, pendientes y cuentas de conchas y mineral de cobre (Figura $N^{\circ} 7$ ), perforadores, petroglifos muebles con diseños lineales paralelos e instrumento de hueso con grabaciones (Figura $N^{\circ} 8$ ). Sobre las estructuras se depositaron restos de comidas colectivas, residuos culturales y sedimentos estériles trasladados desde el exterior, orientados a cubrir los recintos durante eventos ritualísticos hasta conformar un montículo al momento del abandono (De Souza et al., 2010; Núñez y Santoro, 2011).

Varias observaciones actuales confirman que este sitio representa un prototipo de centro ceremonial en vez de un lugar residencial de uso transitorio. A pesar de la ausencia en Tulán-52 de inhumaciones de infantes, fogones estructurados, arte rupestre complejo, muro periférico, ofrendas sofisticadas (iconos metálicos), entre otros, éste presenta varias características estructurales y funcionales en común con el ceremonialismo del templete referido anteriormente, como la acumulación gradual de un montículo sobre las estructuras, derivado de prácticas redundantes de congregación social y consumo de comidas ritualizadas intra y extra recintos.

Las dataciones ${ }^{14} \mathrm{C}$ de ambos sitios indican que fueron ocupados antes de que las estructuras fueran levantadas, presentando similares patrones constructivos básicos con lajas verticales empotradas en el piso estéril. Ya en Tulán-52 se observan grandes bloques monolíticos abatidos, frecuentes en templete de Tulán-54, y al interior de las estructuras tampoco se perciben restos de actividades domésticas. Por otra parte, los espacios interiores de los recintos de Tulán-52 son 
Figura $\mathrm{N}^{\circ} 5$

Preformas de puntas de proyectiles y cuchillo bifacial formatizado del sitio Tulán-52
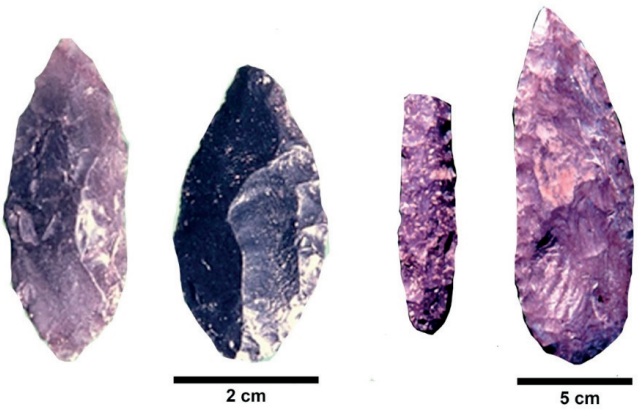

Fuente: Elaboración propia. Archivo fotográfico de Lautaro Núñez.

Figura $N^{\circ} 6$

Mortero arcaico de molienda de hueco cónico agotado y pilón pulido (Tulán-52)
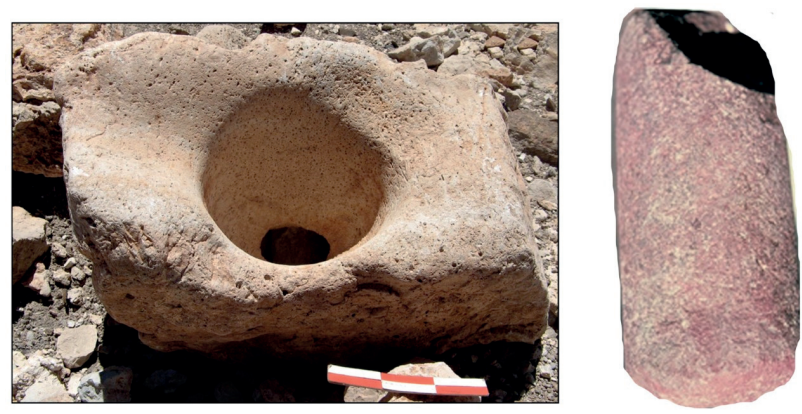

Fuente: Elaboración propia. Archivo fotográfico de Lautaro Núñez.

Figura $\mathrm{N}^{\circ} 7$

Ornamento pectoral perforado de ostión proveniente del Pacífico (Pecten sp.) y cuentas de concha, hueso y mineral de crisocola de color celeste (Tulán-52)

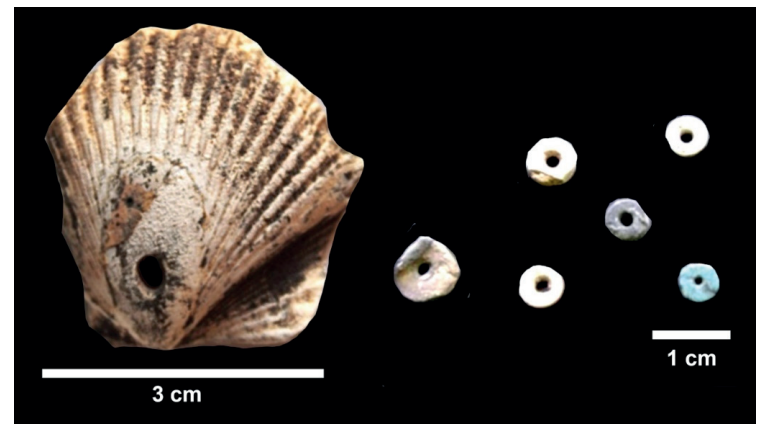

Fuente: Elaboración propia. Archivo fotográfico de Lautaro Núñez. 
Figura $\mathrm{N}^{\circ} 8$

Fragmento de artefacto de hueso con diseños pirograbados y bloque lítico con incisiones grabadas
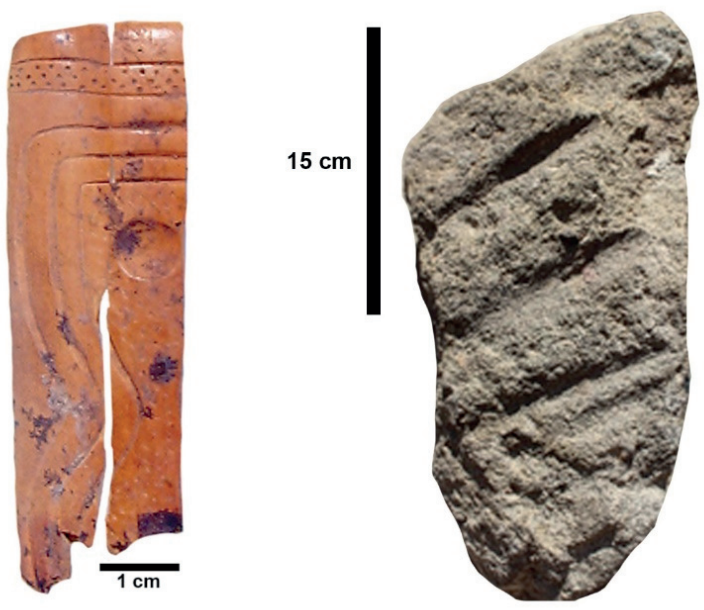

Fuente: Elaboración propia. Archivo fotográfico de Lautaro Núñez.

demasiado estrechos para constituir residencias permanentes o transitorias (Figura № 9). Más bien, se interpretan como espacios con pisos limpios de uso temporal, vinculados con prácticas rituales, interacción social y acceso a comidas preparadas, entre escasos sujetos intra muro, quizás los linajes del liderazgo, mientras que la mayoría subalterna ocupa los espacios abiertos del entorno. De hecho, el registro etnográfico y pictográfico local da cuenta de cacerías colectivas de camélidos conducidas por líderes (Boman, 1991 [1908]; Núñez et al., 2006b), cuyas presas serían las más consumidas durante los festines, al tanto que las especies domésticas se conservarían para su reproducción y adiestramiento.

Esta planificación arquitectónica aglutinada de espacios tan restringidos difiere de otros asentamientos sincrónicos del Arcaico Tardío, asociados a campamentos con estructuras circulares propiamente domésticas de escalas más amplias. Efectivamente, al noreste del salar de Atacama se han descrito grandes estructuras dispersas, asociadas a evidentes actividades cotidianas, con plantas no profundamente excavadas y muros más bajos y menos demandantes en términos de técnicas de construcción, notándose la carencia de montículos sobre los recintos (Agüero y Uribe, 2011; Núñez et al., 2006a).

En Tulán-52, en vez de contar con un gran espacio dividido por muros radiales, rodeado por un muro perimetral con nichos-cámaras alternados, los constructores crearon espacios de particiones agrupando varias estructuras circulares, aunque con fines ceremoniales diferentes al templete (Ej. ausencia de inhumaciones de infantes). Los recintos presentan diámetros que fluctúan entre 140 y $200 \mathrm{~cm}$ y aun otros menores (ver Figura $N^{\circ}$ 9). De modo que la función de las estrechas estructuras de Tulán-52 fue acoger a diversas agrupaciones segmentadas en los primeros actos ritualísticos congregados en torno a comidas preparadas en los abundantes morteros de hueco cónico, localizados junto a los recintos en espacios liberados o sobre los muros y aun en la super- 
Figura $N^{\circ} 9$

Planta de las estructuras semicirculares en el núcleo del sitio Tulán-52

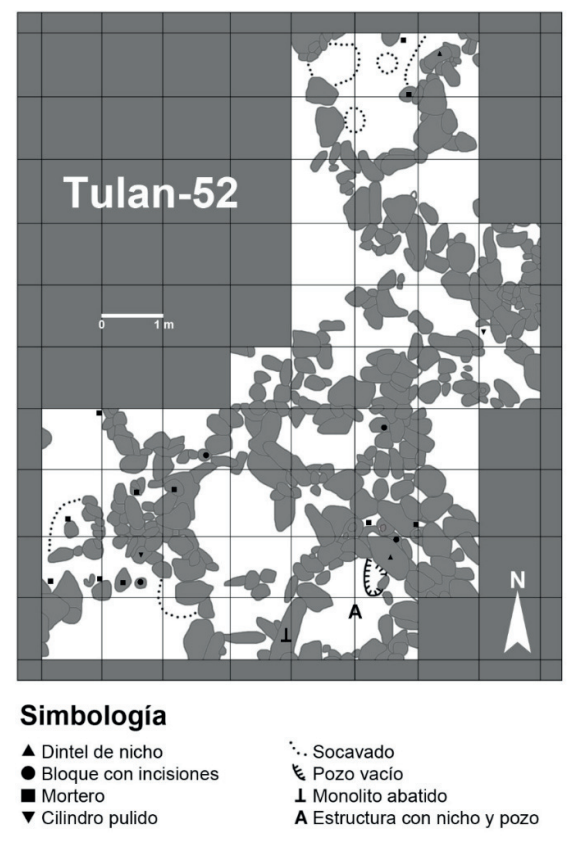

Fuente: Proyecto FONDECYT No 1130917.

ficie del sitio. El rol de los camélidos fue gravitante en términos de consumo y ritualidad, tal como se ha constatado posteriormente en el templete de Tulán-54. Por otra parte, hasta ahora se han localizado, asociados a los recintos de Tulán-52, dos nichos con pilares y dinteles de uso ritual, otra característica ausente en las estructuras residenciales domésticas arcaicas y formativas del área. Esto implica la aparición de un rasgo considerado propio de las construcciones ceremoniales andinas arcaico-formativas (Canziani, 2009; Núñez et al., 2005b: 309). Del mismo modo, se han aplicado lajas verticales empotradas en el piso, asociadas a bloques muebles grabados con incisiones paralelas, una práctica que será más plenamente desarrollada en Tulán-54. Los pisos de las estructuras contienen depresiones artificiales sin una función conocida, aunque algunas contenían restos óseos. Tanto la etnografía local como las evidencias de Tulán-54, las vincularían con ofrendas. En Tulán-52, no obstante, en su mayoría estaban vacías. Una fosa de 0,5 m de diámetro se asocia precisamente con un nicho que contiene en su base bajo el dintel un bloque con incisiones lineales, enfatizando el carácter ceremonial de ese espacio (Figura $\mathrm{N}^{\circ} 10$ ).

Aparte de los actos ceremonialistas en Tulán-52, los eventos de interacción social incluyeron actividades laborales, constituyendo un foco de intensas acciones de talla, haciendo uso de toba volcánica local, pero también de obsidiana (más del 25\% de los artefactos) importada desde las tierras más altas, por lo menos de 100 a $150 \mathrm{~km}$ de distancia. Esta movilidad regional es propia de las prácticas de caza, pastoreo, crianza y de los inicios caravaneros, con posibles comienzos de la división social del trabajo como el adiestramiento caravanero constatado que facilitó el acceso a recursos complementarios de corta y larga distancia en un territorio transectual identitario apro- 
Figura $N^{\circ} 10$

Detalle de la estructura decapada asociada al nicho con dintel (A) y depósito vacío a nivel del piso (B)

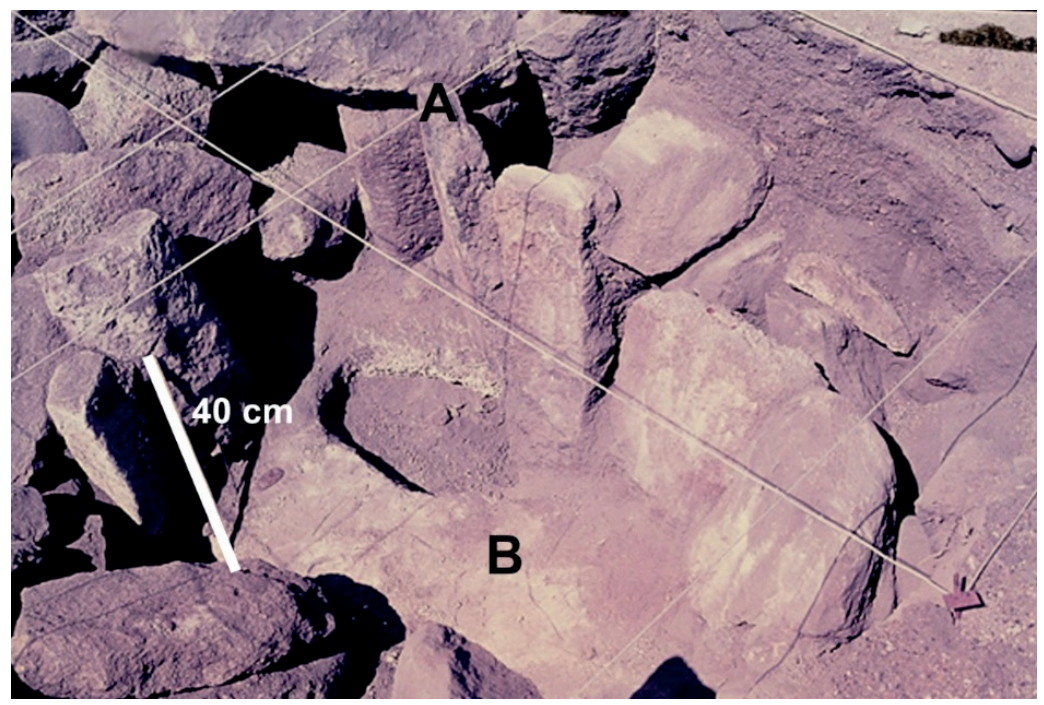

Fuente: Proyecto FONDECYT No 1130917.

piado, tal como lo refleja la distribución de las labores pastoralistas, la circulación interpisos de la materia lítica local (ej. toba Tulán) y la cerámica de la tradición Tilocalar - Los Morros, desde la cuenca lacustre de Meniques hasta el borde del salar de Atacama (López et al., 2013).

La existencia en Tulán-52 de indicadores que constituyen innovaciones en este marco cronológico de movilidad extra local y ritualidad, en términos de amplias redes de intercambio, es demostrada por la presencia de bienes exóticos: obsidiana de la alta puna y trasandina de Argentina, conchas de la costa del Pacífico (Olivia peruviana y Pecten purpuratus), óxidos de cobre locales y foráneos, y madera posiblemente de chonta (Astrocaryum chonta Mart.). Se incluyen piezas de carácter ritual: un cilindro grande como matriz de posibles contenedores líticos de usos ritualísticos, inicios de técnicas de pulimentado, artefacto de hueso pirograbado, además del comienzo del uso de perforadores que serán muy abundantes e, incluso, dominantes en las colecciones líticas intra y extra templete del sitio Tulán-54, vinculados con la producción masiva de cuentas y adornos que cumplían roles ideológicos en el amplio espacio circumpuneño (De Souza et al., 2010).

La alta proporción de implementos de molienda para la preparación de alimentos, algunos con depósitos conspicuos de pigmento rojo, es otra característica compartida en ambos sitios. Sin embargo, los morteros cónicos de Tulán-52 que proceden de ocupaciones arcaicas más tempranas, heredados de la fase Tambillo, están casi todos fracturados en su base exterior una vez que avanzó el agotamiento de sus funciones, siendo otra expresión ritual en términos de ofrendas "matadas". Si bien las prácticas de molienda continuaron en Tulán-54, aquí ocurrió un cambio relevante al aplicar esta vez técnicas de molido por fricción (metates) más que por percusión o machacado. Sin embargo, los metates fracturados también tuvieron roles ceremoniales en el piso del templete al aplicarlos en los bordes de los fogones cercanos a las inhumaciones de los infantes. 
Finalmente, la duración del uso de ambos centros ceremoniales es una característica que los diferencia, ya que las ocupaciones arcaicas en Tulán-52 serían más prolongadas que aquellas que se vincularon con el centro ceremonial de Tulán-54, considerando su tiempo más restringido entre el comienzo y abandono del sitio. Comparten eventos ritualísticos e intercambios sociales colectivos de corta duración, quizás en las estaciones más productivas, con retorno a sus labores habituales, hasta que el sitio estructurado quedó cubierto bajo un depósito de sedimentos, fogones in situ y depósitos secundarios de descartes, también trasladados, alcanzando en Tulán-52 una altura de ca. 1,30 m, y ca. de $2 \mathrm{~m}$ en el caso de Tulán-54. Los depósitos de descartes in situ y aquellos trasladados desde el exterior derivaron principalmente de huesos de camélidos, vinculados a ceremonias de festines ("banquetes"), de acuerdo al tamaño seleccionado de las presas, hasta constituir en ambos sitios túmulos estratificados. Estos cubrieron totalmente las estructuras con la exposición de fogones superficiales, sometidos a erosión subaérea, tal como se observa en el sitio Tulán-52 (Cartajena, 2009; Delgado Aragón, 1971; Núñez et al., 2017) (Figura Nº 11).

Figura $\mathrm{N}^{\circ} 11$

Panorama de las estructuras de Tulán-52. Al fondo se observa el perfil estratigráfico del montículo que cubría el sitio

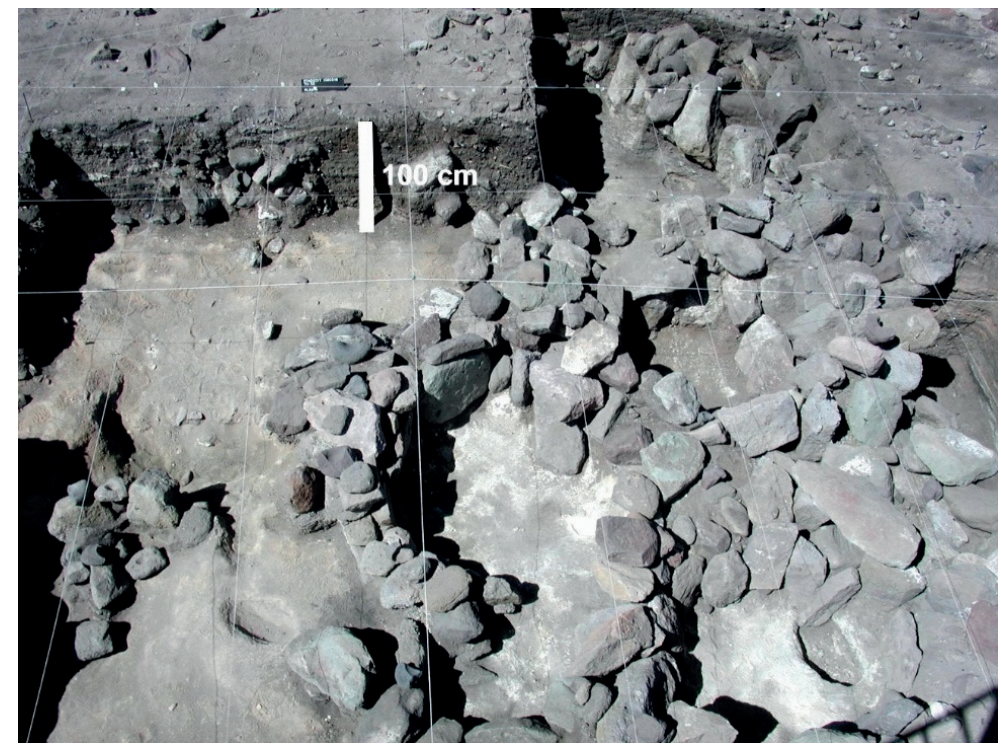

Fuente: Proyecto FONDECYT Nº 1130917.

\section{Conclusiones}

Recientes observaciones en el sitio arcaico tardío Tulán-52 y las colecciones asociadas podrían incluir interpretaciones complementarias a través de argumentos afines, orientadas a proponer más decididamente que este sitio representaría a un prototipo de centro ceremonial donde convergen agrupaciones de distintos espacios dispersos, forrajeros y de caza, estableciéndose un nexo con el centro ceremonial formativo temprano Tulán-54 (De Souza et al., 2010; Núñez et al., 2005b). Se habría procedido en Tulán-52 a intercambios de diversa naturaleza, combinándose 
prácticas rituales y domésticas (ej. preparación de artefactos líticos) en ciertas temporadas de abundancia de recursos durante el ciclo anual, posiblemente en verano cuando se reproducen los camélidos y se reiteran ritos afines de acuerdo a los pastores contemporáneos (Macquarie, 1995). En esos eventos, a juzgar por la abundancia de restos óseos y morteros cónicos de machacado, fue relevante el rol de las comidas durante los encuentros colectivos. Todo lo anterior conduce a la valoración de un particular proceso dinámico de "neolitización", sustentado inicialmente en caza-recolección y domesticación sin dependencia de recursos agrarios (Price, 1985).

Así, donde hoy se advierte un delgado oasis longitudinal rodeado de interfluvios desérticos absolutos, trascurrieron los cambios conducentes al desarrollo pastoralista como factor clave para la consolidación del paisaje social circumpuneño, sustentado en la crianza de camélidos, al parecer con independencia de los procesos de domesticación identificados en los Andes nucleares (Lavallée, 1990). Se considera que el para-sedentarismo de estos cazadores-recolectores avanzados de Tulán-52 los habría conducido a transformaciones complejas con liderazgos capaces de organizar la movilidad de las comunidades locales en torno a cotos de caza colectiva, de acuerdo a la evidencia etnográfica (Boman, 1991 [1908]). Habrían ocurrido movimientos de larga distancia hacia las tierras más altas y el Pacífico, a juzgar por el uso de obsidiana foránea y la presencia de ornamentos de conchas perforadas in situ. Cuando se alcanzó nuevamente un umbral demográfico creciente, estimulado por el retorno del régimen de humedad, los aportes arcaicos-formativos tempranos alcanzaron a consolidar un nuevo modo de vida que trascendió en una escala espacial más amplia. Tulán- 52 contribuyó con la creciente importancia de rituales y prácticas religiosas, vinculadas inicialmente a un parche fértil que las sustentaba en el medio de una crisis climática regional. Las comunidades de la fase posterior Tilocalar, bajo el pleno régimen húmedo, ampliaron la escala y las prácticas pastoralistas cubrieron los principales espacios forrajeros de las cuencas de Atacama y del Loa. Desde la alta puna (Meniques), pasajes intermedios (Pozo Cavado), en ambos bordes de la quebrada Tulán y las playas del salar de Atacama, diversas ocupaciones se movilizaron hacia eventos cíclicos en el locus ceremonial arcaico (Tulán-52) y formativo (Tulán-54), respectivamente (De Souza et al., 2010; Cartajena, 2013; Núñez et al., 2006a). En efecto, la ausencia de asentamientos domésticos cerca de los sitios Tulán-52 y 54 demostraría que las agrupaciones accedieron aquí con propósitos especiales, y la escala y las construcciones, además de los restos de comidas ritualizadas, sugieren que se trata de lugares de congregación de varias comunidades. De modo que la construcción de estos centros ceremoniales podría ser vista como el resultado de un proceso de crecientes prácticas dinámicas de caza y pastoralismo con espacios dispersos de interacción que requerían de un axis mundi (Eliade, 1959). Un centro convergente de carácter regional y devocional de acceso intermitente, con integración social y laboral, en un contexto de liderazgo incipiente y necesidades ritualísticas afines, posiblemente conducente a un amplio incremento de las presas cazadas y al crecimiento de los primeros rebaños domésticos.

En ambos casos la construcción y uso de los dos centros ceremoniales implicaron acciones colectivas como el trasporte y colocación de grandes losas y, más tarde, el aprovisionamiento y preparación de comidas, incluido el mantenimiento de fogones. El manejo de estas variables y otras fuerzas de tareas sugiere el control y aun posiblemente la coerción sobre las agrupaciones subalternas por elites emergentes, quizás de carácter religioso (Arnold, 1996; Earle, 1997; Hastorf, 2008; Kuijt, 1996). En consecuencia, se propone que más bien el resultado del proceso arcaico de "neolitización", asociado a la emergencia de complejidad social en la circumpuna atacameña, fue la raíz de los cambios que condujeron a la consolidación de la sociedad formativa temprana. 
Este proceso fue sostenido por las notables innovaciones que ocurrieron durante ca. los dos milenios que separan a Tulán-52 del 54, asociado con el incremento del uso de camélidos salvajes y domésticos, incluyendo su aplicación en el trasporte de bienes, como también con las primeras prácticas hortícolas. Precisamente, el templete de Tulán-54 ejemplifica la culminación de este proceso con el uso de cerámica, alucinógenos, la manufacturación de bienes de valor, metalurgia del oro, sacrificios de infantes y frecuentes expresiones de arte rupestre. Sin duda alguna los rasgos y ofrendas de más valor fueron todos registrados en el complejo colectivo del templete. El hecho de que hasta ahora en ambos sitios no se han registrado inhumaciones de individuos adultos con objetos que indiquen el acceso diferenciado a bienes de status o que reflejen grados crecientes de riqueza, ha dificultado la determinación, con certeza, sobre la naturaleza jerárquica de la elite. Es posible que se hayan organizado a través de líneas jerárquicas con acceso directo y control de la riqueza y fuerzas de tareas, o más bien agrupado a través de la modalidad corporativa (Blanton et al., 1996; Feinman, 1995, 2000, 2016). Se corresponderían con aquello que Renfrew (1974) también llamó grupos orientados en jefaturas, precisamente caracterizados por espacios con ritualidad monumental, donde el poder era compartido con grupos a nivel de membresías con acciones no conducentes a la acumulación de riqueza individual.

Con independencia del modo en que se organizó la elite local, dado el mínimo consumo de plantas domésticas, reflejado en la ausencia de restos de maíces en los depósitos estratificados de Tulán-54, y la importante ingesta de camélidos domésticos y salvajes en ambas fases: Puripica-Tulán y Tilocalar, las necesidades de productos agrarios no eran factores gravitantes en este particular proceso de "neolitización" del ámbito circumpuneño.

Finalmente, Tulán-52 es una evidencia por ahora excepcionalmente particular entre comunidades cazadoras de los Andes meridionales, sin embargo, se han identificado estructuras vinculadas con prácticas ritualísticas en distintos ambientes. Al respecto, junto al Pacífico, en los Andes septentrionales, durante el Holoceno Temprano se han descrito estructuras y rasgos de uso ceremonial en contextos de caza a través de encuentros sociales durante la fase Payjan (Dillehay, 2011). Por otra parte, en las tierras altas del centro sur andino se han registrado estructuras y rasgos por los ca. $2850 \mathrm{AC}$, asociados a actos ceremonialistas, intercambios sociales y festines entre comunidades de cazadores-recolectores móviles en transición hacia prácticas hortícolas y pastoralistas (Aldenderfer, 1991). También hay descripciones etnográficas de los cazadores SeIk'nam del extremo sur americano sobre el uso de estructuras en prácticas chamanísticas, eventos sociales congregados y comidas ritualizadas (Borrero, 2007; Guráieb, 2001; Gusinde, 1982). De modo que es posible identificar estructuras en comunidades de cazadores-recolectores móviles, donde las actividades domésticas pueden asociarse a prácticas rituales al margen de modos de vida sedentarios (Bradley, 2004, 2005).

Por lo mismo, el proceso de cambios entre el Arcaico Tardío y el Formativo Temprano se alinea por su escala particular con otros centros de neolitización, documentados en el Cercano Oriente, Japón o China, donde también los antecede la adopción de una economía agropastoralista. Estos casos igualmente sustentan la tesis que la emergencia de complejidad social no fue el resultado de cambios económicos per se, sino que los estímulos sociales y rituales actuaron en la base del proceso. En este contexto se sugiere que las transformaciones tecnológicas y económicas fueron demandadas por élites incipientes que constantemente requerían acumular riqueza y nuevos símbolos de estatus (Chapman, 2003; Hayden, 1998, 2014). 
Las comunidades neolíticas y/o arcaicas tardías que articularon ecorefugios, como en este caso, circularon primero entre recursos circunscritos y luego en espacios más abiertos durante la interfase seco-húmeda, compatibilizando modos de vida dinámicos que incluyeron la agregación social temporal de base ritualista. Se esperaría que bajo estas condiciones surgiesen jerarquías sociales capaces de crear regímenes políticos embrionarios, basados en ritualidad y poder. Esta orientación explicaría la emergencia arcaico-formativa de monumentalidad, labores corporativas, producción de excedentes de objetos simbólicos y la recepción de bienes exóticos. El clímax del proceso se establecería a través de la movilización de agrupaciones formativas tempranas que entre sus labores móviles cotidianas y el retorno a sus asentamientos incluyeron el acceso al centro ceremonial, donde se repiten los encuentros de alta visibilidad, participación litúrgica, festines e interacciones generosas, incluidos intercambios sociales (Artursson et al., 2016; Hayden, 2014; Hastorf, 2008). El acercamiento a los cambios formativos entre el riesgo, experimentación, innovación y mayor producción de bienes implicó más control socioeconómico, sostenido por un sofisticado aparato ritual que caracterizó a estas sociedades intermedias, insertas en cambios cruciales que requerían de un soporte ideológico, estimulado por una intensa relación entre humanos y camélidos.

\section{Referencias bibliográficas}

ABBOtT, M.; WOLFE, B.; WOLFE, A.; SELTZER, G.; ARAVENA, R.; MARK, G.; POLISSA, P.; RODBELL, D.; ROWE, H. \& VUILLE, M. Holocene paleohydrology and glacial history of the Central Andes using multiproxy lake sediment studies. Palaeogeography, Palaeoclimatology, Palaeoecology, 2003, Vol. $194, N^{\circ} 1-3$, p. 123-138.

AGÜERO, C. y URIBE, M. Las sociedades formativas de San Pedro de Atacama: asentamiento, cronología y proceso. Estudios Atacameños, 2011, N 42, p. 53-78.

ALDENDERFER, M. Continuity and change in ceremonial structures at late preceramic Asana, southern Peru. Latin American Antiquity, 1991, Vol. 2, №3, p. 227-258.

ARNOLD, J.E. Power and labor among complex hunter-gatherers and other intermediate societies. In: ARNOLD, J.E. (editor). Emergent complexity: The evolution of intermediate societies. Ann Arbor: International Monographs in Prehistory, Archaeological Series 9, 1996, p. 59-73.

ARTURSSON, M.; EARLE, T. \& BROWN, J. The construction of monumental landscapes in low density societies: New evidence from the Early Neolithic of Southern Scandinavia (4000-3300 BC) in comparative perspective. Journal of Anthropological Archaeology, 2016, Vol. 41, p. 1-18.

ASCHERO, C.; ELKIN, D. y PINTAR, E. El aprovechamiento de recursos faunísticos y producción lítica en el precerámico tardío. Un caso de estudio: Quebrada Seca-3 y la puna meridional Argentina. Actas del XI Congreso Nacional de Arqueología Chilena, 1991, Tomo II, p. 101-114.

BELL, C. Ritual theory, ritual practice. Oxford: Oxford University Press, 1992.

BENEDICT, J. Getting away from it all: A study of man, mountains and the two-drought altithermal. Southwestern Lore, 1978, Vol. 45, № 3, p. 1-12. 
BINFORD, M. \& KOLATA, A. Late Holocene paleohydrology, lake-level fluctuation and Andean civilization in the Lake Titicaca Basin. In: Central Andean Paleoclimate Workshop, Tucson (Arizona), 2001.

BLANCO, A. Práctica social, memoria y ritual en Cogotas I: esbozo teórico para un enfoque renovado. Trabajos de Prehistoria, 2011, Vol. 68, №1, p. 123-146.

BLANTON, R.E.; FEINMAN, G.M.; KOWALEVSKI, S.A. \& PEREGRINE, P. N. A dual-processual theory for the evolution of Mesoamerican civilization. Current Anthropology, 1996, Vol. 37, No 1, p. 1-14.

BOMAN, E. Antiguedades de la región andina de la República Argentina y del desierto de Atacama. Argentina: Gómez, D. (traductor), Universidad de Jujuy, 1991 [1908].

BONNICHSEN, R.; STANFORD, D. \& FASTOOK, J. L. Environmental change and developmental history of human adaptive patterns: The Paleoindian case. In: RUDDIMAN, W.F. \& WRIGHT, H.E. (editors). Geology of North America, Vol. 3, Adjacent oceans during the last deglaciation. Boulder, Colorado: The Geological Society of America, 1987, p. 424-430.

BORRERO, L. Los Selk'nam (Onas). Evolución cultural en Tierra del Fuego. Buenos Aires: Editorial Galerna, 2007.

BRADLEY, R. A life less ordinary: the ritualization of the domestic sphere in later prehistoric Europe. Cambridge Archaeological Journal, 2004, Vol. 13, № 1, p. 5-23.

BRADLEY, R. Ritual and domestic life in prehistoric Europe. London / New York: Routledge, 2005.

BROWN, J.A. \& KELLY, J.E. Surplus labor, ceremonial feasting and social inequality at Cahokia: a study in social process. In: MOREHART, CH.T. \& DE LUCIA, K. (editors). Surplus: The politics of production and the strategies of everyday life. Colorado: University Press of Colorado, 2015, p. 221-244.

BRÜCK, J. Ritual and rationality. Some problems of interpretation in European archaeology. Journal of Archaeology, 1999, Vol. 2, Nº 3, p. 313- 344.

CANZIANI, J. Ciudad y territorio en los Andes. Contribución a la historia del urbanismo prehispánico. Lima: Fondo Editorial Pontificia Universidad Católica de Lima, 2009.

CAPRILES, J. Mobile communities and pastoralist landscapes during the formative in the central altiplano of Bolivia. Latin American Antiquity, 2014, Vol. 25, № 1, p. 3-26.

CARTAJENA, I. Explorando la variabilidad morfométrica del conjunto de camélidos pequeños durante el Arcaico Tardío y el Formativo Temprano, Norte de Chile. Revista del Museo de Antropología, 2009, Vol. 2, No 1, p. 199-212.

CARTAJENA, I. Faunal assemblages from the Middle Holocene: Environmental and cultural variability in the western slope of the Puna de Atacama. Quaternary International, 2013, Vol. 307, p. 31-37. 
CARTAJENA, I.; NÚÑEZ, L. \& GROSJEAN, M. Camelid domestication on the western slope of the Puna de Atacama, northern Chile. Anthropozoologica, 2007, Vol. 42, N² 2, p. 155-173.

CHAPMAN R. L. Archaeologies of complexity, London: Routledge, 2003.

CONNERTON, P. Como las sociedades recuerdan. Cambridge: Cambridge University Press, 1989.

DE SOUZA, P.; CARTAJENA, I.; NÚÑEZ, L. y CARRASCO, C. Cazadores-recolectores del arcaico tardío y desarrollos de complejidad social en la puna de Atacama: las evidencias del sitio Tulán-52 (norte árido de Chile). Revista Werken, 2010, Vol. 13, N² 2, p. 91-118.

DELGADO ARAGON, J.G. El señalakuy. Allpanchis Phuturinqa, 1971, Vol. 3, № 3, p. 185-197.

DESCOLA, P. Constructing natures: symbolic ecology and social practice. In: DESCOLA, P. y PÁLSSON, G. (editores). Nature and society: anthropological perspectives. London: Routledge, 1996, p. 83-102.

DIETLER, M. \& HERBICH, I. Feasts and labor mobilization: dissecting a fundamental economic practice. In: DIETLER, M. \& HAYDEN, B. (editors). Feasts: Archaeological and ethnographic perspectives on food, politics, and power. Washington DC: Smithsonian, 2001, p. 240-264.

DIETLER, M. \& HAYDEN, B. Digesting the feast -good to eat, good to drink, good to think: an introduction. In: DIETLER, M. \& HAYDEN, B. (editors). Feasts: Archaeological and ethnographic perspectives on food, politics, and power. Washington: Smithsonian, 2001, p. 1-20.

DILLEHAY, T. La arquitectura en los espacios transitorios de la tradición Paiján. Boletín de Arqueología PUCP, 2011, № 15, p. 145-163.

EARLE, T. How chiefs came to power: the political economy in prehistory. Stanford: Stanford University Press, 1997.

ELIADE, M. The sacred and the profane: The nature of religion. New York: Trask, W.R. (traductor), Harcourt, Brace \& World Inc., 1959.

FEINMAN, G.M. The emergence of inequality: a focus on theory and process. In: PRICE, T.D. \& FEINMAN, G.M. (editors). Foundations of Social Inequality. New York: Plenum, 1995, p. 225-280.

FEINMAN, G.M. Corporate/Network: new perspectives on models of political action and the Puebloan Southwest. In: SCHIFFER, M. B. (editor). Social theory in archaeology. Salt Lake City: The University of Utah Press, 2000, p. 31-61.

FEINMAN, G.M. Variation and change in Archaic States: Ritual as a mechanism of sociopolitical integration. In: MURPHY, J.M.A. (editor). Ritual and archaic states. Gainesville: University Press of Florida, 2016, p. 1-22. 
GEYH, M.A.; GROSJEAN, M.; NUÑEZ, L. \& SCHOTTERER, U. Radiocarbon reservoir effect and the timing of the Late-Glacial/Early Holocene humid phase in the Atacama Desert (Northern Chile). Quaternary Research, 1999, Vol. 52, N², p. 143-153.

GOSDEN, C. \& LOCK, G. Prehistoric histories. The past in the past: the reuse of ancient monuments. World Archaeology, 1998, Vol. 30, No 1, p. 2-12.

GROSJEAN, M. \& NÚÑEZ, L. Late glacial, early and middle Holocene environment, human occupation and resource use in the Atacama (Northern Chile). Geoarchaeology, 1994, Vol. 9, N 4, p. 271-286.

GROSJEAN, M.; GEYH, M.A.; MESSERLI, B. \& SCHOTTERER, U. Late-Glacial and Early Holocene lake sediments, groundwater formation and climate in the Atacama Altiplano 22-24 ${ }^{\circ}$. Journal of Paleolimnology, 1995, Vol. 14, № 3, p. 241-252.

GROSJEAN, M.; NÚÑEZ, L.; CARTAJENA, I. \& MESSERLI, B. Mid-Holocene climate and culture change in the Atacama Desert, northern Chile. Quaternary Research, 1997, Vol. 48, № 2, p. 239-246.

GROSJEAN, M.; VAN LEEUWEN, J. F.; VAN DER KNAAP, W. O.; GEYH, M. A.; AMMANN, B.; TANNER, W.; MESSERLI, B.; NÚÑEZ, L.; VALERO GARCES, B. \& VEIT, H. A $22.000{ }^{14} \mathrm{C}$ year B. P. sediment and pollen record of climate change from Laguna Miscanti $23^{\circ} \mathrm{S}$, Northern Chile. Global and Planetary Changes, 2001a, Vol. 28, p. 35-51.

GROSJEAN, M.; AMMANN, B.; CAMACHO, M.; GEYH, M. A.; KERN, R.; KULEMEYER, J.; KULL, C.; JOEZEN, D.; SCHOTTERER, U.; SCHREIER, H.; TANNER, W.; VALERO GARCES, B.; VAN LEEUWEN, V. \& VEIT, H. Late-Glacial/Early Holocene lake level, glacial histories in the Atacama Altiplano and potential climate mechanisms. In: Central Andean Paleoclimate Workshop, Tucson (Arizona), 2001b.

GROSJEAN, M.; CARTAJENA, I.; GEYH, M. A. \& NÚÑEZ, L. From proxy data to paleoclimate interpretation: the mid-Holocene paradox of the Atacama Desert, northern Chile. Palaeogeography, Palaeoclimatology, Palaeoecology, 2003, Vol. 194, No 1-3, p. 247-258.

GROSJEAN, M.; NÚÑEZ, L. \& CARTAJENA, I. Cultural response to climate change in the Atacama Desert. In: SMITH, M. \& HESSE, P. (editores). $23^{\circ}$ South: The archaeology and environmental history of the Southern Deserts. Canberra: National Museum of Australia, 2005a, p. 156-171.

GROSJEAN, M.; NÚÑEZ, L. \& CARTAJENA, I. Paleoindian occupation of the Atacama Desert, Northern Chile. Journal of Quaternary Science, 2005b, Vol. 20, N 7-8, p. 643-653.

GROSJEAN, M.; SANTORO, C.M.; THOMPSON, L.G.; NÚÑEZ, L. \& STANDEN, V.G. Mid-Holocene climate and culture change in the South central Andes. In: ANDERSON, D.G.; MAASCH, K.A. \& SANDWEISS, D. H. (editors). Climate change and cultural dynamics: a global perspective on Mid-Holocene transitions. San Diego: Academic Press, 2007, p. 51-115.

GURAIEB, A.G. La agregación en cazadores-recolectores: aportes desde la etnografía y la arqueología. Relaciones de la Sociedad Argentina de Antropología, 2001, Tomo 26. Disponible en Internet: http://sedici.unlp.edu.ar/bitstream/handle/10915/20580/Documento_completo.pdf?sequence=1 
GUSINDE, M. Los indios de Tierra del Fuego. Los Selk'nam. Buenos Aires: Centro Argentino de Etnología Americana, 1982, Tomo I, Vol. 2.

HASTORF, C. Archaeological Andean rituals: performances, liturgy and meaning. In: KYRIAKIDIS, E. (editor). The archaeology of ritual. Los Angeles: Cotsen Institute of Archaeology, University of California, 2007, p. 77-107.

HASTORF, C.A. The formative period in the Titicaca basin.IEn: SILVERMAN, H. \& ISBELL, W.H. (editors). The Handbook of South American Archaeology. New York: Springer, 2008, p. 545-561.

HAYDEN, B. Practical and prestige technologies: the evolution of material systems. Journal of Archaeological Method and Theory, 1998, Vol. 5, № 1, p. 1-55.

HAYDEN, B. Fabulous feast: A prolegomenon to the importance of festing. In: DIETLER, M. \& HAYDEN, B. (editors). Feast: Archaeological and ethnographic perspectives on food, politics and power. Washington DC: Smithsonian, 2001, p. 23-64.

HAYDEN, B. The power of feast from prehistory to the present. Cambridge: Cambridge University Press, 2014.

HESSE, B. Archaeological evidence for camelid exploitation in the Chilean Andes. Säugetierkundliche Mitteilungen, 1982, Vol. 30, № 3, p. 201-211.

HOLDEN, T. Evidence of prehistoric diet from Northern Chile: Coprolites, gut contents and flotation samples from Tulán Quebrada. World Archaeology, 1991, Vol. 22, №3, p. 321-331.

INGOLD, T. Society, nature and the concept of technology. Archaeological Review from Cambridge, 1990, Vol. 9, No 1, p. 4-17.

KAULICKE, P. Las fiestas y sus residuos: Algunas reflexiones finales. Boletín de Arqueología PUCP, 2005, N 9, p. 387- 402.

KUIJT, I. Negotiating equality through ritual: A consideration of late Natufian and Prepottery Neolithic A period mortuary practices. Journal of Anthropological Archaeology, 1996, Vol. 15, p. 313336.

LATORRE, C.; BETANCOURT, J.L.; RYLANDER, K.A.; QUADE, J. \& MATTHEI, O. A vegetation history from the arid prepuna of Northern Chile $\left(22^{\circ}-23^{\circ} \mathrm{S}\right)$ over the last 13.500 years. Palaeogeography, Palaeoclimatology, Palaeoecology, 2003, Vol. 194, N 1-3, p. 223-246.

LATORRE, C.; BETANCOURT, J.L.; RECH, J. A.; QUADE, J.; HOLMGREN, C.; PLACZEK, C.; MALDONADO, A.; VUILLE, M. \& RYLANDER, K. A. Late Quaternary history of the Atacama Desert. In: SMITH, S. \& HESSE, P. (editors). $23^{\circ} \mathrm{S}$ : The archaeology and environmental history of the southern deserts. Canberra : National Museum of Canberra Press, 2005, p. 70-90. 
LAVALLÉE, D. La domestication animale en Amérique du Sud. Bulletin de l'Institut Français d'Études Andines, 1990, Vol. 19, Nº 1, p. 25-44.

LÓPEZ, P.; CARTAJENA, I. y NÚÑEZ, L. Análisis de isotopos estables en colágeno de huesos de camélidos de Quebrada Tulán, Puna de Atacama, periodo Formativo Temprano (ca. 3100-2400 BP). Chungara, Revista de Antropología Chilena, 2013, Vol. 45, N² 2, p. 237-247.

MACQUARIE, K. Mitos, leyendas y ceremoniales: llamas, alpacas y dioses de las montañas. En: FLORES OCHOA, J.; MACQUARIE, K. y PORTÚS, J. (editores). Oro de los Andes: las Ilamas, alpacas, vicuñas y guanacos de Sudamérica. Barcelona: Ediciones Jordi Blassi, 1995, p. 145-209.

MESSERLI, B.; GROSJEAN, M.; BONANI, G.; BÜRGI, A.; SCHOTTERER, U.; SCHREIER, H. \& VUILLE, M. Climate change and natural resource dynamics of the Atacama Altiplano during the last 18,000 years: A preliminary synthesis. Mountain Research and Development, 1993, Vol. 13, N² 2, p. 117-127.

MOSELEY, M.E. Climate, culture and punctuated change: New data, new challenges. The Review of Archaeology, 1997, Vol. 18, № 1, p. 19-20.

NÚÑEZ, L. y SANTORO, C. M. El tránsito arcaico-formativo en la Circunpuna y Valles Occidentales del centro sur andino: hacia los cambios neolíticos. Chungará, Revista de Antropología Chilena, 2011, Vol. 43, Nº especial 1, p. 487-730.

NÚÑEZ, L.; GROSJEAN, M. y CARTAJENA, I. Un ecorefugio oportunístico en la puna de Atacama durante eventos áridos del Holoceno Medio. Estudios Atacameños, 1999, № 17, p. 91-125.

NÚÑEZ, L.; GROSJEAN, M. \& CARTAJENA, I. Human occupations and climate change in the Puna de Atacama, Chile. Science, 2002, Vol. 298, N 5594, p. 821-824.

NÚÑEZ, L.; GROSJEAN, M. y CARTAJENA, I. Ocupaciones humanas y paleoambientes en la Puna de Atacama. San Pedro de Atacama: Instituto de Investigaciones Arqueológicas y Museo, Universidad Católica del Norte-Taraxacum, 2005a.

NÚÑEZ, L.; CARTAJENA, I.; CARRASCO, C. y DE SOUZA, P. El templete de Tulán y sus relaciones formativas panandinas (norte de Chile). Bulletin de I'Institut Français d'Études Andines, 2005b, Vol. 34, No 3, p. 299-320.

NÚÑEZ, L.; CARTAJENA, I.; CARRASCO, C.; DE SOUZA, P. y GROSJEAN, M. Emergencia de comunidades pastoralistas formativas en el sureste de la Puna de Atacama. Estudios Atacameños, 2006a, $\mathrm{N}^{\circ} 32$, p. 93-117.

NÚÑEZ, L.; CARTAJENA, I.; CARRASCO, C.; DE SOUZA, P. y GROSJEAN, M. Patrones, cronología y distribución del arte rupestre arcaico tardío y formativo temprano en la cuenca de Atacama. En: FIORE, D. y PODESTÁ, M. (editores). Tramas en la piedra. Producción y usos del arte rupestre. Buenos Aires: Sociedad Argentina de Antropología, 2006b, p. 191-204. 
NÚÑEZ, L.; MC ROSTIE, V. y CARTAJENA, I. Consideraciones sobre la recolección vegetal y la horticultura durante el Formativo Temprano en el sureste de la cuenca de Atacama. Darwiniana, 2009, Vol. $47, N^{\circ} 1$, p. 56-75.

NÚÑEZ, L.; CARTAJENA, I. \& GROSJEAN, M. Archaeological silence and ecorefuges: Arid events in the Puna of Atacama during the Middle Holocene. Quaternary International, 2013, Vol. 307, p. 5-13.

NÚÑEZ, L.; CARTAJENA, I.; CARRASCO, C.; LÓPEZ, P.; RIVERA, F.; DE SOUZA, P.; SANTANDER, B. y LOYOLA, R. Nuevas excavaciones en Tulán-54. Revelando la arquitectura ceremonial durante el Formativo Temprano en la puna de Atacama. Revista Chilena de Antropología, 2016, Vol. 34, p. 65-79.

NÚÑEZ, L.; CARTAJENA, I.; CARRASCO, C.; LÓPEZ, P.; DE SOUZA, P.; RIVERA, F. y SANTANDER, B. Presencia de un centro ceremonial formativo temprano en la circumpuna de Atacama. Chungará, Revista de Antropología Chilena, 2017, Vol. 49, №1, p. 3-33.

NÚÑEZ, L.; LOYOLA, R.; CARTAJENA, I.; LÓPEZ, P.; SANTANDER, B.; MALDONADO, A.; DE SOUZA, P. \& CARRASCO, C. Miscanti-1: Human occupation during the arid Mid-Holocene event in the high altitude lakes of the Atacama Desert, South America. Quaternary Science Reviews, 2018, Vol. 181, p. 109-122.

PRICE, T.D. Complex foragers in Southern Scandinavia. En: PRICE, T.D. \& BROWN, J.A. (editors). Prehistoric hunter-gatherers. The emergence of cultural complexity. Orlando: Academic Press, 1985.

RECH, J.; QUADE, J. \& BETANCOURT, J. Late quaternary paleohydrology of the Central Atacama Desert (lat. $22^{\circ}-24^{\circ} \mathrm{S}$ ), Chile. Geological Society of America Bulletin, 2002, Vol. 114, № 2, p. 334-348.

RECH, J. A.; PIGATI, J. S.; QUADE, J. \& BETANCOURT, J. L. Re-evaluation of mid-Holocene deposits at Quebrada Pupirica, Northern Chile. Palaeogeography, Palaeoclimatology, Palaeoecology, 2003, Vol. 194, p. 207-222.

RENFREW, C. Beyond a subsistence economy: The evolution of social organization in prehistoric Europe. In: MOORE, C.B. (editor). Reconstructing complex societies. Cambridge: Bulletin of the American Schools of Oriental Research, Supplement 20, 1974, p. 69-95.

RICHARDIN, P.; HERAULT, C. \& MUSSARD, S. Rapport d'étude au C2RMF et datation par le carbone 14 d'un petit condor en bois recouvert d'or. 2017, Manuscrito.

SANDWEISS, D.H.; MELNNIS, H.; BURGER, R.; CANO, A.; OJEDA, B.; PAREDES, R.; SANDWEISS, M.C. \& GLASCOCK, M.D. Quebrada Jaguay: Early South American maritime adaptations. Science, 1998, Vol. 281, N5384, p. 1830-1832.

SCHMIDT, K. "Ritual centers" and the neolithisation of Upper Mesopotamia. Neo-Lithics, 2005, Vol. 2, No 05, p. 13-21. 
SELTZER, G.O. \& HASTORF, C.A. Climatic change and its effects on prehispanic agriculture in the Central Peruvian Andes. Journal of Field Archaeology, 1991, Vol. 17, № 4, p. 397-414.

SYLVESTRE, F.; SERVANT-VILDARY, S.; FOURNIER, M. \& YBERT, J.P. Lake level chronology on the Southern Bolivian Altiplano $\left(18^{\circ}-23^{\circ} \mathrm{S}\right)$ during late-glacial time and the Early Holocene. Quaternary Research, 1999, Vol. 51, № 2, p. 54-66.

VALERO GARCES, B.; GROSJEAN, M.; SCHWALB, A.; GEYH, M.; MESSERLI, B. \& KELTS, K. Limnogeology of Laguna Miscanti: evidence for mid to late Holocene moisture changes in the Atacama Altiplano (Northern Chile). Journal of Paleolimnology, 1996, Vol. 16, No 1, p. 1-21. 